\title{
ALTAS HABILIDADES NA EDUCAÇÃO INFANTIL: RELATO DE CASO PSICOPEDAGÓGICO
}

\author{
ALTAS HABILIDADES EN EDUCACIÓN INFANTIL: UN REPORTE DE CASO \\ PSICOPEDAGÓGICO
}

HIGH SKILLS IN CHILD EDUCATION: A PSYCHOPEDAGOGICAL CASE REPORT

Maria Isabel de ARAÚJO' ${ }^{1}$

RESUMO: O presente trabalho de investigação caracteriza-se como estudo de caso psicopedagógico com objetivo de saber/identificar as características e comportamentos de superdotação/altas habilidades de um aprendente da educação infantil de uma instituição escolar do município de Uberlândia-MG. Os instrumentos utilizados na pesquisa foram a observação, questionários, entrevista/anamnese aplicados à equipe pedagógica da escola, professora da sala regular, aprendente e familiares. Também foi feita uma análise de documentos/materiais acadêmicos do aprendente. Após esse processo de avaliação inicial, os resultados apresentados indicaram-nos comportamentos acima da média com características de altas habilidades do tipo acadêmico e produtivo-criativa e potencial elevado nas áreas das inteligências linguística, espacial, lógico-matemático. Considerando fatores como desenvolvimento diferenciado para sua faixa etária, foi sugerido um acompanhamento, atenção e trabalho sistemático, nas áreas das inteligências supracitadas para verificar intensidade e constância, bem como desenvolvimento do potencial.

PALAVRAS-CHAVE: Identificação psicopedagógica. Altas habilidades/superdotação. Educação infantil.

RESUMEN: Este trabajo de investigación se caracteriza como un estudio de caso psicopedagógico con el objetivo de conocer / identificar las características y comportamientos de superdotación / altas habilidades de un alumno de la primera infancia de una institución escolar en la ciudad de Uberlândia-MG. Los instrumentos utilizados en la investigación fueron observación, cuestionarios, entrevistas / anamnesis aplicados al equipo pedagógico de la escuela, al maestro de clase regular, al alumno y a los miembros de la familia. También se realizó un análisis de los documentos / materiales académicos del estudiante. Después de este proceso de evaluación inicial, los resultados presentados indicaron comportamientos superiores al promedio con altas habilidades académicas y creativas-creativas y un alto potencial en las áreas de inteligencia lingüística, espacial, lógica-matemática. Teniendo en cuenta factores como el desarrollo diferenciado para su grupo de edad, se sugirió un seguimiento, atención y trabajo sistemático en las áreas de las

\footnotetext{
${ }^{1}$ Secretaria Municipal de Educação de Uberlândia (SME), Uberlândia - MG - Brasil. Coordenadora de Ensino da Educação Especial na Prefeitura Municipal de Uberlândia (PMU). Mestre em Educação (UNITRI). Especialista em Psicopedagogia Clínica e Institucional (UFU) e especialista em Educação Especial (UFC). Atua no Atendimento Educacional Especializado e como professora convidada do Curso de Especialização em Psicopedagogia da FACED/UFU. Membro do Grupo de Estudos e Pesquisas em Altas Habilidades/Superdotação (GEPAHS)/UFU e do Grupo de Estudos e Pesquisas em Psicopedagogia Escolar (GEPPE). ORCID: https://orcid.org/0000-0003-4104-7764. E-mail: psmariaisabel@gmail.com
} 
inteligencias antes mencionadas para verificar la intensidad y la constancia, así como el desarrollo potencial.

PALABRAS CLAVE: Identificación psicopedagógica. Altas habilidades/superdotación. Educación Infantil.

ABSTRACT: This work is characterized as a psychopedagogical case study and had as objective attend/identify the characteristics and behaviors of high skills/giftedness of a school unit of early childhood education for psychopedagogical evaluation in Uberlândia, Minas Gerais. The research instruments used were observation, questionnaires, interview / anamnesis applied to pedagogical team of the school, teacher of the regular classroom, learner and parents. Also, there were made analysis of documents/academic materials of the learner. After this initial evaluation process, the presented results indicated us above-average behaviors with high skills characteristics about academic and productive-creative with a high potential in the areas of linguistic intelligence, spatial, logical-mathematical. Considering factors such as differentiated development for their age group, it was suggested a systematic follow-up, attention and work in the areas of the above-mentioned intelligences to verify intensity and constancy, as well as development of potential.

KEYWORDS: Psychopedagogical identification. High skills/giftedness. Early childhood education.

\section{Introdução}

Uma educação inclusiva de todos e para cada um procura garantir o cumprimento do direito constitucional indispensável a qualquer estudante, desde que oferte uma organização pedagógica nas escolas e práticas de ensino que atendam as diferenças, sem discriminação, beneficiando a todos com equidade. Para tanto, as escolas devem conhecer e compreender as especificidades e o potencial para/do processo de aprendizagem de seus aprendentes.

Tendo como princípio essa afirmativa e atendendo pedido da coordenação pedagógica de uma instituição particular de educação infantil do município de Uberlândia, iniciamos o trabalho com o objetivo de conhecer melhor o contexto do aprendente e identificar as possíveis características/comportamentos de altas habilidades/superdotação (AH/SD), tendo como base a abordagem qualitativa na modalidade de estudo de caso psicopedagógico. Os dados foram coletados a partir de questionários elaborados por pesquisadores da área, utilizando os indicadores AH/SD de Freitas e Pérez (2012), ${ }^{2}$ Vieira (2005) e análise da lectoescrita de Ferreiro (2001). O referencial teórico utilizado fundamentou-se numa visão ampla sobre a inteligência (GARDNER, 2000) e pelo conceito de superdotação (RENZULLI, 2004). O estudo contou com as seguintes etapas de identificação/avaliação psicopedagógica:

${ }^{2}$ Os instrumentos foram construídos com base nas teorias das inteligências múltiplas de Gardner $(1995 ; 2000)$ e de Superdotação de Renzulli (1986).

Doxa: Rev. Bras. Psico. e Educ., Araraquara, v. 21, n. 2, p. 255-268, jul./dez. 2019. 
entrevista com professor de sala de aula regular e coordenação pedagógica da escola; entrevista com os pais; observação do cotidiano escolar; atividades de enriquecimento individuais e em sala.

A relevância deste estudo não está apenas na identificação, mas também em conhecer, compreender e orientar a escola e familiares a respeito das alternativas de desenvolvimento do potencial.

\section{Fundamentação teórica}

Atualmente, no Brasil, o direito à educação está assegurado mediante compromisso legal de garantir o acesso público dos aprendizes da Educação Especial no sistema de ensino regular, com intuito de promover acessibilidade. ${ }^{3}$ Nessa perspectiva, houve crescente movimento e estudos para uma educação inclusiva, que respeite as singularidades, o desenvolvimento humano, as diferentes formas e estilos de aprender e as múltiplas inteligências. Consequentemente, no decorrer dos anos, houve uma ampliação do conceito de inteligência que, de certa forma, além de influenciar na mudança de definição, acarretou a modificação e a compreensão da identificação e atendimento da categoria de aprendentes que apresentam AH/SD. Mesmo que a concepção de inteligência tenha se modificado nos últimos anos percebe-se que muitos desafios relacionados à superdotação precisam ser vencidos. Nesse sentido, a identificação, de acordo com os teóricos atuais, deve contemplar um contexto mais amplo.

Assim, conforme Virgolin:

[...] os instrumentos de identificação mais utilizados nos programas de atendimento aos alunos com altas habilidades/superdotação têm sido: (a) testes psicométricos; (b) escalas de características; (c) questionários; (d) observação do comportamento; (e) entrevistas com a família e professores, entre outros (VIRGOLIM, 2007, p. 55).

Verifica-se, portanto, que a concepção de AH/SD e os processos para identificação evoluíram de uma visão unidirecional para multidimensional, seguindo os novos conceitos sobre inteligência, abrangendo múltiplos indicadores, incluindo a observação, a dialogicidade e o contexto vivencial do aprendiz.

Nessa linha de pensamento, Azevedo (2010) observou que a identificação precisa contemplar múltiplos aspectos, contextos e variados instrumentos cujas fontes de informações

\footnotetext{
3 “Acessibilidade não mais se restringe ao espaço físico, ou seja, à dimensão arquitetônica”, classifica-se em seis dimensões: arquitetônicas, comunicacionais, atitudinais, programáticas, metodológicas e instrumentais.
} 
englobem aprendizes, professores, colegas de turma e familiares, entre outros. Para o autor, a instituição escolar deve ser um espaço de identificação e acolhimento desses talentos. Considerando essa perspectiva, para que ocorra a identificação pelos profissionais que avaliam as $\mathrm{AH} / \mathrm{SD}$, faz-se necessária, que ela esteja referendada por fundamentação teórica coerente com a perspectiva da inclusão e das múltiplas inteligências.

Stemberg (1996), da Universidade de Yale, examina e estuda os múltiplos fatores na composição da inteligência em sua Teoria Triádica, segundo a qual a pessoa pode ser inteligente de três formas: pelo uso das inteligências analítica, criativa e prática. Para pessoas singulares com habilidades diferentes, situações ímpares são necessárias para identificação e possíveis encaminhamentos no contexto educacional e geral.

Renzulli (2004) afirma que a superdotação é uma condição a ser desenvolvida desde que haja interação apropriada entre ambiente, pessoa e área do talento. O referencial teórico proposto por ele é importante no processo de identificação da pessoa com AH/SD no contexto da educação inclusiva e denomina-se "Modelo dos três anéis". Esse processo de identificação do comportamento é mais flexível e prioriza aspectos qualitativos e dinâmicos, abordando o papel da família, do contexto escolar do aprendente e suas influências. Para esse autor, existem dois tipos de superdotação: a acadêmica e a produtivo-criativa.

Outro autor que traz um referencial sólido nessa área é Gardner (1983), com a estrutura denominada "Teoria das Inteligências Múltiplas", a qual envolve um conjunto de habilidades, talentos e capacidades mentais. Define inteligência como "um potencial biopsicológico para processar informações que podem ser ativadas num cenário cultural, para solucionar ou criar produtos que sejam valorizados numa cultura" (GARDNER, 2000, p. 47). Esse autor entende que existem nove formas de inteligência: inteligência linguística; inteligência lógico-matemática; inteligência musical; inteligência corporal-cinestésica; inteligência espacial; inteligência interpessoal; inteligência intrapessoal; inteligência naturalista; e inteligência existencial.

No caso em questão, para proceder à identificação, utilizamos os construtos teóricos de Gardner (1995) e de Renzulli (2004). Esses autores são referências atuais para construção de instrumentos e processos de avaliação/observação das características e indicadores das AH/SD em educação, assim como na construção de propostas de atendimentos com base no conceito multidimensional, dinâmico e produtivo criativo do potencial de inteligências superiores.

Mediante esse universo, procurando atender à solicitação da instituição escolar, em sua necessidade de avaliação/identificação e encaminhamentos específicos para o aprendiz com características de $\mathrm{AH} / \mathrm{SD}$, propusemo-nos a realizar um estudo do caso. 


\section{Método}

O presente trabalho consiste em uma abordagem qualitativa, com o objetivo de obter informações para identificar indicativos de altas habilidades/superdotação. Essa abordagem abre caminho para uma visão holística, possibilitando conhecer as características e os comportamentos de AH/SD do aprendente em situações escolares e familiares, bem como por estar em consonância com os objetivos propostos de aprofundamento nas situações da realidade cotidiana do aprendente e, portanto, descrever a realidade dele (TRIVIÑOS, 1987). Nesse contexto, optamos pelo estudo de caso psicopedagógico, por permitir, conforme Yin (2001, p. 21), "uma investigação para se preservar as características holísticas e significativas dos eventos da vida real - tais como ciclos de vida individuais".

Os instrumentos utilizados na pesquisa foram: questionários, entrevista/anamnese aplicada à equipe pedagógica da escola, professora da sala regular, aprendente e pais, seguindo critérios de indicadores de AH/SD de Freitas e Pérez (2012) ${ }^{4}$ e Vieira (2005). ${ }^{5}$ Houve também avaliação pedagógica de indicadores de AH/SD do aprendente por meio de situações-problema, raciocínio lógico e lectoescrita (FERREIRO, 2001). Outra forma de coleta de dados foi a análise de documentos/materiais acadêmicos do aprendente, observação do cotidiano escolar e aplicação de atividades de enriquecimento curricular envolvendo criatividade, fluência verbal, flexibilidade de pensamento, lógico-matemática, bem como conhecimentos gerais.

\section{Apresentação dos resultados}

Os resultados foram avaliados de acordo a literatura alusiva ao conceito de AH/SD de Gardner (1995), Renzulli (2004), Perez, (2002) e Vieira, (2005).

\section{Informes preliminares sobre o aprendente a partir de breve entrevista com o professor de sala de aula e coordenação pedagógica da escola.}

De acordo com Winner (1998), existem várias formas de identificação dessa clientela, mas todas devem contemplar uma leitura contextualizada do desempenho do aluno, sua história acadêmica e familiar, bem como uma observação sistemática de suas habilidades e interesses em contextos e situações sociais de aprendizagem diferentes.

\footnotetext{
${ }^{4}$ Instrumento elaborado por Freitas e Pérez (2012).

${ }^{5}$ Ficha de identificação da primeira infância elaborada por Vieira (2005).
} 
Os dados das entrevistas revelaram-nos um perfil alegre, criativo, comunicativo, extremamente curioso, querendo sempre saber o porquê das coisas. Indicam que o aprendente por vezes apresenta inquietação e desejo por novas experiências, além das cotidianas na sala, e isso acontece quando termina a atividade e os demais colegas ainda não concluíram. Relatam que ele possui persistência em atividades do seu interesse e não as abandona, enquanto não estiver concluída. Ainda segundo dados coletados, o aprendente não gosta de levar brinquedos de casa para a escola e nos jogos/atividades apresenta dificuldades em "perder", pois gosta sempre de ser o melhor. De acordo com respostas da professora da classe, nas atividades sugeridas em sala, ele vai além do que é solicitado com muita autonomia e independência. A equipe relata ainda que o aprendente já foi acelerado devido à sua perspicácia e desenvolvimento acadêmico à frente dos demais colegas. Segundo a professora, ele adora manifestar sua opinião e sempre apresenta alternativas/respostas para resolução de problemas sejam de ordem acadêmica ou em jogos e brincadeiras que envolvem lógica.

\section{Informes preliminares sobre o aprendente a partir de breve entrevista com os pais}

Como a coleta de informações com familiares contribui com o processo de identificação de características particulares do aprendente, a princípio, foi realizada breve entrevista com o objetivo de resgatar dados importantes para esclarecer fatos observados pela escola, bem como saber quais oportunidades o aprendente vivenciou que possibilitaram novas aprendizagens e desenvolvimento de talentos.

A mãe relatou que o filho de 4 anos cursa o $2 .^{\circ}$ Período da Educação Infantil, nasceu de 38 semanas, engatinhou aos 8 meses e andou com 11 meses e 15 dias (mais ou menos). Iniciou a fala por volta de 1 ano e com 2 anos já sabia o alfabeto, porque a babá ensinou-o, e aos 3 anos já estava lendo. Afirmaram que aprendeu a ler "sozinho" aos 3 anos de idade e argumentam que ele tem excelente memória fotográfica em tudo o que ouve e lê, bem como ótima leitura e oralidade, com português fluente e rapidez de pensamento. Quando está em casa, a área de maior interesse é assistir ao desenho e jogar com aparelhos celulares, computadores e iPads, nos quais apresenta muita habilidade. Seu maior prazer é dialogar sobre assuntos diversos e escrever sobre situações que o instigam. Ainda segundo os pais, o filho apresenta-se como uma criança de poucos amigos, mas, quando está em grupo, sempre se interessa pelas atividades dos outros, procurando liderar e conduzir para atividades de seu interesse. É muito disciplinado com a utilização do seu tempo, principalmente ao executar as tarefas escolares. De acordo com os pais, o filho adora ir ao shopping e clube. No aspecto emocional, algo que chama atenção dos familiares é a dificuldade em receber um "não". 
Entendem que a precocidade de seu filho se apresenta por características atípicas, principalmente no interesse e habilidades relativas à leitura e escrita, raciocínio lógico matemático, atividades/descobertas e linguagem, confirmando o que dizem Sabatella e Cupertino (2007) ao relatarem que crianças precoces demonstram capacidade específica prematuramente desenvolvida. Segundo relato da mãe, essa precocidade não parece se manifestar em todas as áreas, pois, em natação e na organização de atividades cotidianas, o aprendente apresenta comportamento "comum", como todas as demais crianças. Após coleta de dados por meio das entrevistas/anamnese, com a família e escola, foram aplicados questionários conforme descritos na metodologia.

Relativamente à análise dos documentos/materiais acadêmicos, observa-se uma frequência de comportamentos de altas habilidades observados pela equipe pedagógica da escola, professora da sala regular, aprendente e pais, que nos permitiram tecer algumas considerações.

Uma delas é referente à atividade do desenho livre com escrita da história, em que apresentou precocidade na leitura, com fluência e pontuação, sendo capaz de escrever corretamente e sem auxílio todas as palavras que constavam nas atividades, inclusive aquelas com sílabas complexas. Muito questionador, apresentou vocabulário extenso para sua idade, demostrando aprender e assimilar rapidamente. Usou as palavras de forma ativa, historiando ou escrevendo. É importante ressaltar que, segundo Gardner (1995), a inteligência linguística é a competência intelectual mais ampla e mais democraticamente compartilhada na espécie humana. De acordo com o questionário, o aprendente apresentou excelente domínio linguístico.

Outro aspecto presente na coleta de dados diz respeito à inteligência musical, a qual possibilita a compreensão, discriminação, percepção, expressão e transformação das formas musicais (ritmo, tom, melodia, timbre dos sons). De todas as habilidades que o indivíduo pode desenvolver, segundo Gardner (1995), nenhuma surge mais cedo do que o talento musical. Os componentes centrais são as capacidades de produzir e apreciar ritmos, tom e timbre, e a apreciação das formas de expressividade musical. Nesse caso, o aprendente apresentou algumas vezes domínio musical, sendo necessário explorar melhor essa inteligência.

No tocante às inteligências relacionadas aos objetos: apresentou bom raciocínio lógico matemático. Este é caracterizado pela "capacidade que se origina do confronto com o mundo dos objetos, visto que é através da ordenação e reordenação dos objetos e da avaliação de suas quantidades que a criança adquire seu conhecimento inicial, que é basilar nesta habilidade" (VIEIRA, 2005, p. 36). 
Na inteligência espacial, responsável pela habilidade de orientação no mundo físico e de alcançar transformações sobre essas percepções, o aprendente praticamente apresentou todas as características de domínio.

Referente à inteligência corporal-cenestésica encontra-se na média geral. Segundo Vieira (2005), esta se manifesta pela capacidade de resolver problemas ou elaborar produtos utilizando o corpo, seus movimentos ou partes deste, com estilo altamente individual e hábil, para finalidades expressivas.

$\mathrm{Na}$ análise da inteligência relacionada ao conhecimento sobre o mundo vivo, apresentou desenvolvimento de acordo com os colegas de seu convívio, apesar de demonstrar curiosidade e interesse pelo mundo que o cerca. Segundo Vieira (2005, p. 45), "um naturalista demonstra grande interesse no reconhecimento e na classificação de numerosas espécies da flora e da fauna e de seu meio ambiente". Nesse caso, o aprendente não expressou interesse acima da média.

Concernente às inteligências de relação pessoal (intrapessoal e interpessoal), o aprendente exibiu características significativas dessa segunda, visto o gosto pela convivência com as crianças de sua respectiva faixa etária e de dialogar e conviver com adultos, confirmando algumas das características da inteligência interpessoal, que é a "habilidade de lidar com outras pessoas e, por meio delas, planejar e concretizar objetivos".

$\mathrm{Na}$ inteligência intrapessoal caracterizada pela competência de distinguir e lidar com as emoções, o aprendente demostrou pouca habilidade na capacidade de agir com flexibilidade em situações que o incomodam. É importante ressaltar que tanto a inteligência inter e intrapessoal quanto a linguística estão sempre presentes na nossa vida, pois constantemente estamos interagindo com outras pessoas.

Pontuadas as inteligências em maior evidência no caso, procuramos tecer uma relação com a teoria de Renzulli (2004), um os autores em que nos embasamos. Assim, encontramos presente a concepção de superdotação de Renzulli (2004) quando o aprendente apresenta grande parte das características de habilidades acima da média, criatividade $e$ comprometimento com a tarefa.

Considerando os dados levantados referentes a habilidades acima da média, o aprendente demostrou interesse em determinados domínios como games, iPad, diálogos sobre assuntos diversos e escritos sobre situações que o instigam. Apresentou grande capacidade em processar as informações e integrar experiências que venham a resultar em respostas apropriadas e inovadoras. Exibiu capacidade de se envolver no pensamento abstrato e desempenhou com sucesso as atividades propostas, encontrando-se em um nível superior ao de sua idade cronológica. 
O comportamento relativo à criatividade apareceu em evidência no aprendente ao ser bastante questionador, imaginativo e original em seu pensamento e na resolução de problemas. Exibiu traços de busca constante por conhecimento, com persistência, dedicação, fluência e flexibilidade, sinalizando para escola e pais a necessidade de promover especialização/ambiência para que potencialize esses campos, antes que o produto final aconteça.

Relativamente à motivação ou envolvimento com a tarefa, mostrou persistência e prática dedicada em concluir as atividades propostas em mais de uma área do saber, além de ter muita autoconfiança, acreditando na própria habilidade.

Enfim, nota-se que estão presentes no aprendiz as categorias de AH/SD acadêmicas e a produtivo-criativa de Renzulli (2004), porém em maior intensidade e interesse a matemática e o português, mais especificamente a comunicação oral e escrita. Respectivamente às áreas das inteligências múltiplas, o estudo apresentou maior evidência da linguística, lógicomatemático e espacial. Isso confirma os estudos e pesquisas sobre a teoria das Inteligências Múltiplas de Gardner (1995), ao afirmar que a pessoa com AH/SD pode mostrar uma combinação de várias e diferentes inteligências. A partir dos resultados obtidos, foram feitos encaminhamentos para escola e familiares, de forma a contribuir com a inclusão escolar do aprendente.

\section{Considerações finais: ainda que preliminar}

Tendo como referencial a singularidade das AH/SD, a análise dos domínios apresentados pelo aprendente nas diferentes áreas das inteligências, bem como pelo exame dos questionários/entrevistas com os pais e profissionais da escola, verificou-se a necessidade de investigação, aprofundamento e acompanhamento do caso. De acordo com Virgolim (2007), a convergência das informações compõe a identificação da AH/SD, mas ela somente é significativa se for realizada com o objetivo de oferecer atendimento especializado ao aluno conforme suas possibilidades e interesses.

Assim, considerando que o aprendente apresenta características de precocidade/altas habilidades e entendendo que crianças precoces têm alguma habilidade específica prematuramente desenvolvida em qualquer área do conhecimento, algumas intervenções psicopedagógicas foram encaminhadas. 


\section{a) Para escola}

Cientes das possíveis habilidades em áreas do saber e fazer, não obstante a precocidade ser um indicativo da superdotação é prudente que a identificação do aprendente possa contar com um acompanhamento a fim de aferir a evolução de seus talentos, bem como ter uma ambiência que proporcione o desenvolvimento do potencial nas áreas das suas habilidades. Também, estabelecer ações pedagógicas adequadas que venham provocar o aprendente para que não seja apenas consumidor de conhecimento, mas também produtor de saberes e fazeres. Nessa perspectiva, sugere-se que a instituição escolar organize grupos de acompanhamento, oferta do Atendimento Educacional Especializado (AEE), estabelecimento de parcerias para atividades de enriquecimento pedagógicas a fim de continuar em processo de identificação das AH/SD e atender às necessidades do aprendente (ARAÚJO; TELLES; FERREIRA, 2016).

Portanto, como nos afirmam Galbraith e Delisle (1996), a inexistência de incentivo, de experiências de aprendizagem ou de vida enriquecedoras, bem como a falta de reconhecimento das capacidades e potencialidades do aprendente, poderão concorrer para o desuso dessas habilidades e sua consequente estagnação. Nesse sentido, foram encaminhados, a princípio, alguns procedimentos necessários ao desenvolvimento do aprendente, quais sejam:

- Avaliação psicológica do aprendente, caso a escola ou familiares desejem, pois não é necessário laudo médico ou psicológico para diagnosticar altas habilidades/superdotação (BRASIL, 2014);

- Coleta de dados/parecer de uma equipe multidisciplinar como: relatório de professor, trabalhos diários do aprendente, relato de profissionais da escola que convivem com ele, relato de amigos, familiares, psicopedagogo, para acompanhamento e registro de seu potencial;

- Registro no censo escolar como público-alvo da educação especial - “Altas Habilidades/Superdotação";

- Oferta de práticas diversificadas e acompanhamento contínuo, pois o aprendente diferencia-se dos demais integrantes do grupo em função do desenvolvimento prematuro de determinadas habilidades, apresentando necessidades distintas das de seus colegas;

- Pensar formas de aceleração possíveis (ex. saltar uma ou mais séries, aceleração parcial de matérias, entre outros);

- Elaborar o planejamento estratégico que lhes permitirá programar, no ritmo e na intensidade possíveis, o preparo dos professores e dos demais profissionais da escola, bem como as adequações curriculares necessárias;

- Realizar parcerias com instituições acadêmicas ou comunitárias, como 
universidades, centros tecnológicos, centros de cultura, escolas de música, escolas de idiomas, para atender às necessidades específicas do aprendente;

- Proporcionar ao professor conhecimentos para identificar as áreas de potencialidade do aprendente, observando como estão sendo utilizadas na sala de aula e contexto escolar;

- Planejar as atividades de ensino de forma a promover o crescimento de acordo com os ritmos, possibilidades, interesses e necessidades da turma e do aprendente, levando em consideração agrupamentos por estilos de aprendizagem;

- Orientar o professor a ser facilitador do processo de ensino aprendizagem, tendo flexibilidade na conduta pedagógica e nas relações entre seus aprendentes, que possibilite $o$ crescimento de talentos e habilidades, desafios e contextos interessantes que motivem a aprendizagem;

- Trabalhar com atividades de enriquecimento extracurricular: planejamento de atividades de enriquecimento a serem desenvolvidas em paralelo com a programação normal da série na qual se inserem os aprendentes;

- Elaboração de fichas de conteúdos estimulantes, desafiadores e curiosos para estudos independentes a todo o grupo escolar; cantinhos de aprendizagem, experimentando agrupamentos e reagrupamentos, para estimular o desenvolvimento de potenciais;

- Estimular a participação dos aprendentes na elaboração de projetos de investigação ou de pesquisas de acordo com seus interesses particulares ou suas habilidades.

Enfim, a equipe poderá realizar um estudo de caso aprofundado, de forma a colher subsídios para construir o plano individualizado de ensino e contribuir com o professor da sala comum para algumas particularidades da aprendizagem do aprendente identificado. Por conseguinte, será possível efetivar atividades de enriquecimento e aprofundamento nas diversas áreas em que se manifesta a precocidade, bem como oportunizar momentos de desenvolvimento global e de harmonização dos aspectos dificultadores de seu potencial.

\section{b) Recomendações para família}

Algumas alternativas foram repassadas, entre elas, que participem de encontros mensais de Grupos Operativos na escola ou em parceria com o grupo de estudo da universidade, com a finalidade de debater a precocidade do seu filho, trocar experiências, ideias, esclarecer dúvidas, socializar procedimentos, bem como ampliar o conhecimento acerca do que seja precocidade e altas habilidades. Também foram orientados a:

- Oferecer alternativas estimuladoras ao filho, levando-o a museus, feiras científicas, exibições artísticas, permitindo que ele se expresse a respeito;

- Fornecer sempre ao filho estimulação visual, auditiva, verbal e corporal-cinestésica, 
bem como uma ambiência que desafie e instigue sua imaginação e inspiração, adequado para a sua idade;

- Praticar com o filho o aprendizado da empatia, da compreensão, do respeito à diferença, e características individuais das pessoas e das relações saudáveis entre todos com que convive;

- Procurar programas/atendimentos adequados para o desenvolvimento das áreas de sua precocidade/altas habilidades que oportunizem a seu filho a consciência dos seus aspectos emocionais.

Diante do exposto, escola e família devem considerar a concepção das múltiplas inteligências ao analisar o perfil de aprendizagem do aprendiz, de forma a desenvolver uma prática pedagógica coletiva e/ou individual pertinente ao estilo/habilidades identificados. Enfim, promover o refinamento das habilidades e o desenvolvimento das funções complexas do pensamento do aprendiz, associadas à motivação, interesse, gerando entusiasmo e imaginação criativa.

\section{REFERÊNCIAS}

ARAÚJO, M. I.; TELLES, P. M. C.; FERREIRA, L. R. C. Alunos com altas habilidades/superdotação no ensino fundamental $\left(5 .^{\circ}\right.$ ao $9 .^{\circ}$ ano) de uma escola pública mineira: identificação e encaminhamentos. Revista Educação e Políticas em Debate, v. 5, n. 2, p. 198-209, ago./dez. 2016, ISSN 2238-8346.

AZEVEDO, S. M. L.; METTRAU, MarsylBulkool. Altas habilidades/superdotação: mitos e dilemas docentes na indicação para o atendimento. Psicol. Cienc. Prof. [online]. v. 30, n. 1, p. 32-45, 2010,ISSN 1414-9893. Disponível em: http://dx.doi.org/10.1590/S141498932010000100004. Acesso em: 07 jul.2019.

BRASIL. Decreto n. ${ }^{\circ}$ 6.949, de 25 de agosto de 2009. Dispõe sobre a Convenção Internacional sobre os Direitos das Pessoas com Deficiência e seu Protocolo Facultativo, assinados em Nova York, em 30 de março de 2007. Disponível em: http://www.planalto.gov.br/ccivil_03/_ato2007-2010/2009/decreto/d6949.htm. Acesso em: 25 abr. 2017.

BRASIL. MEC/SECADI/DPEE. Nota Técnica n. 04/2014. Orientação quanto a documentos comprobatórios de alunos com deficiência, transtornos globais do desenvolvimento e altas habilidades/superdotação no Censo Escolar. Brasília, 2014.

FERREIRO, E. Reflexões sobre alfabetização. Tradução e Horácio Gonzales. 24. ed. São Paulo: Cortez, 2001.

FREITAS, S. N.; PÉREZ, S. G. P. B. Altas habilidades/superdotação: atendimento especializado. Marília: ABPEE, 2012. 
GALBRAITH, J.; DELISLE, J. The gifted kid's survival guide: a teen hanbook. Minneapolis: Free Spirit Publishing,1996.

GARDNER, H. Inteligências múltiplas: a teoria na prática. Porto Alegre: Artes Médicas, 1995.

GARDNER, H. Estruturas da mente: A teoria das Inteligências Múltiplas. Porto Alegre: Artes Médicas, 1983.

GARDNER, H. Inteligência - Um Conceito Reformulado. Rio de Janeiro Ed. Objetiva, 2000.

GARDNER, H. Mentes que mudam: a arte e a ciência de mudar as nossas ideias e as dos outros. Tradução Maria Adriana Veríssimo Veronese. Porto Alegre: Artmed, 2005.

GUIMARÃES, G. G.; OUROFINO, V. T. A. T. Estratégias de identificação do aluno com altas habilidades/superdotação. In: FLEITH, D. S. (Org.). Altas habilidades/superdotação: orientação a professores. Brasília: Ministério da Educação Secretaria de Educação Especial, 2007. v. 1.

RENZULLI, J. S. The three-ring conception of giftedness: a developmental model for creative productivity. In: RENZULLI, J. S.; REIS, S. M. (Eds.). The triad reader. Mansfield Center: Creative Learning, 1986.

RENZULLI, J. S. O que é esta coisa chamada superdotação e como a desenvolvemos?. Tradução Susana Graciela Pérez Barrera Pérez. Educação, Porto Alegre, v. 5, n. 1, p. 77-131, jan./abr. 2004. Disponível em: https://www.marilia.unesp.br/Home/Extensao/papah/o-que-eesta-coisa-chamada-superdotacao.pdf. Acesso em: 12 nov. 2016.

SABATELLA, M. L.; CUPERTINO, C. M. B. Práticas educacionais de atendimento ao aluno com altas habilidades /superdotação. In: FLEITH, D. S. (Org.). A construção de práticas educacionais para alunos com altas habilidades/superdotação: orientação a professores. Brasília: Ministério da Educação, Secretaria de Educação Especial, 2007. v. 1.

STERNBERG, R. J. Successful intelligence: how practical and creative intelligence determine success in life. New York: Simon \& Schuster, 1996.

TRIVIÑOS, A. N. S. Introdução à pesquisa em ciências sociais: a pesquisa qualitativa em educação. São Paulo: Atlas, 1987.

VIEIRA, N. J. W. Viagem a "mojave-óki!": a trajetória na identificação das altas habilidades/superdotação em crianças de quatro a seis anos. 2005. Tese (Doutorado) Programa de Pós-Graduação em Educação, Universidade Federal do Rio Grande do Sul, Porto Alegre, 2005.

VIEIRA, N. J. W. Uma trajetória na identificação de altas habilidades/superdotação em educação infantil. In: FREITAS, S. N. (Org.) Educação e altas habilidades/superdotação: a ousadia de rever conceitos e práticas. Santa Maria: Editora da UFSM, 2006. p. 89-107.

VIRGOLIM, A. M. R. Altas habilidades/superdotação: encorajando potenciais. Brasília: Ministério da Educação, Secretaria da Educação Especial, 2007. 
YIN, Robert K. Estudo de caso. Planejamento e métodos. 2. ed. Porto Alegre: Bookman, 2001.

WINNER, E. Crianças superdotadas: mitos e realidades. Porto Alegre: Artes Médicas, 1998.

\section{Como referenciar este artigo}

ARAÚJO, Maria Isabel de. Altas habilidades na educação infantil: relato de caso psicopedagógico. Doxa: Rev. Bras. Psico. e Educ., Araraquara, v. 21, n. 2, p. 255-268, jul./dez. 2019. e-ISSN: 2594-8385. DOI: https://doi.org/10.30715/doxa.v21i2.13092

Submetido em: 20/02/2019

Aprovado em: 20/07/2019

Publicado em: 01/08/2019 